Journal of Elemantary School (JOES)

Volume 1, No 1, Juni 2018

e-ISSN : 2615-1448

p-ISSN : 2620-7338

DOI : https://doi.org/10.31539/joes.v1i1.242

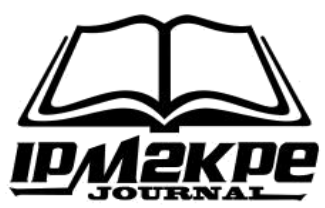

\title{
UPAYA MENINGKATKAN KEMAMPUAN MEMBUAT KALIMAT TANYA MELALUI METODE TUTOR SEBAYA DI KELAS I SEKOLAH DASAR NEGERI 25 LUBUKLINGGAU
}

\author{
Sumarni \\ SD Negeri 25 Lubuklinggau \\ sumarni2018@gmail.com
}

\begin{abstract}
ABSTRAK
Tujuan penelitian ini adalah untuk mengetahui penerapan metode tutor sebaya dapat meningkatkan kemampuan siswa kelas II SD Negeri 25 Lubuklinggau dalam membuat kata tanya. Metode yang digunakan dalam penelitian ini adalah menggunkana pendekatan Penelitian Tindakan Kelas (PTK) yang diawali oleh data pratindakan dan dua kali pelaksanaan siklus penelitian. Hasil data tes pada pratindakan dari 24 siswa, siswa yang mendapat nilai 65 atau telah tuntas sebanyak 14 orang atau $58,33 \%$ dari jumlah siswa. Sedangkan siswa yang mendapat nilai kurang dari 65 atau belum tuntas sebanyak 10 orang atau 41,67\%, dengan nilai ratarata kelas 63,75. Pada siklus I terjadi peningkatan perolehan nilai. Siswa yang telah tuntas sebanyak 17 siswa atau 70,83\% sedangkan yang belum tuntas sebanyak 7 orang atau 29,17\% dengan nilai rata-rata 67,08. Ini terjadi peningkatan sebesar 3,33 atau 5,23\%. Siklus II juga mengalami peningkatan, dari 24 siswa yang telah tuntas sebanyak 22 siswa atau 91,67\% dan yang belum tuntas sebanyak 2 siswa atau 8,33\% dengan nilai rata-rata 75,21. Jika dihitung peningkatan dari nilai pratindakan sampai siklus II terjadi peningkatan sebesar yaitu 11,61\%. Berdasarkan data tersebut hipotesis yang dikemukan dalam penelitian ini terbukti, bahwa dengan penerapan metode tutor sebaya dapat meningkatkan kemampuan membuat kalimat tanya siswa kelas I SD Negeri 25 Lubukkinggau.
\end{abstract}

Kata Kunci : Kemampuan, Tutor Sebaya, Kalimat Tanya

\section{ABSTRACT}

The purpose of this research is to know the application of peer tutor method can improve the ability of second grade students of SD Negeri 25 Lubuklinggau in making a question word. The method used in this research is using the Class Action Research approach (PTK) which is preceded by pratindakan data and twice the implementation of the research cycle. The results of test data on pratindakan of 24 students, students who scored 65 or have completed as many as 14 people or $58.33 \%$ of the number of students. While students who scored less than 65 or not completed as many as 10 people or $41.67 \%$, with an average grade of 63.75. In the first cycle there is an increase in value gains. Students who have completed as many as 17 
students or $70.83 \%$ while unfinished as many as 7 people or $29.17 \%$ with an average value of 67.08. This is an increase of 3.33 or 5.23\%. Cycle II also increased, from 24 students who have completed as many as 22 students or $91.67 \%$ and who have not completed as many as 2 students or $8.33 \%$ with an average value of 75.21 . If the calculated increase of pratindakan value until cycle II there is an increase of $11.61 \%$. Based on these data the hypothesis that was found in this study proved, that with the application of peer tutor method can improve the ability to make sentences asked students of class I SD Negeri 25 Lubukkinggau.

Keywords: Ability, Peer Tutor, Sentence Question

\section{PENDAHULUAN}

Bahasa dibentuk oleh kaidah aturan serta pola yang tidak boleh dilanggar agar tidak menyebabkan gangguan pada komunikasi yang terjadi. Kaidah, aturan dan polapola yang dibentuk mencakup tata bunyi, tata bentuk dan tata kalimat. Agar komunikasi yang dilakukan berjalan lancar dengan baik, penerima dan pengirim bahasa harus menguasai bahasanya. Bahasa adalah suatu sistem dari lambang bunyi arbitrer yang dihasilkan oleh alat ucap manusia dan dipakai oleh masyarakat komunikasi, kerja sama dan identifikasi diri. Bahasa lisan merupakan bahasa primer, sedangkan bahasa tulisan adalah bahasa sekunder.

Mengingat pentingnya makna berbahasa, maka pemerintah telah menetapkan bahwa bahasa Indonesia sebagai salah satu mata pelajaran utama di lembaga-lembaga formal, mulai dari tingkat sekolah dasar sampai ke perguruan tinggi. Dikarenakan belajar bahasa Indonesia pada hakekatnya adalah belajar berkomunikasi maka pembelajaran bahasa Indonesia selalu diarahkan untuk meningkatkan keterampilan siswa dalam berkomunikasi baik secara lisan maupun tertulis. Menurut Hadiningsih (2004) keterampilan berbahasa mempunyai empat komponen yaitu : keterampilan menyimak, keterampilan berbicara, keterampilan membaca, dan keterampilan menulis. Dengan keempat keterampilan tersebut seseorang diharapkan dapat berkomunikasi dan dapat menggunakan bahasa Indonesia dengan baik dan benar (Ali, 2003). Agar kegagalan siswa menyerap pengetahuan dan keterampilan berbahasa Indonesia tidak menumpuk, maka guru yang bertanggungjawab dalam merancang, melaksanakan, menilai dan menindaklanjuti kegiatan pembelajaran, Penggunaan metode yang tepat dan bervariasi akan dapat dijadikan sebagai alat motivasi ekstrinsik dalam kegiatan belajar mengajar di sekolah.

Bertolak dari pengalaman peneliti sebagai seorang guru SD Negeri 25 Lubuklinggau, diketahui bahwa siswa kelas I SD Negeri 25 Lubuklinggau secara umum belum dapat menggunakan bahasa Indonesia yang baik dan benar seperti yang diharapkan dalam tujuan umum dan khusus pembelajaran yang tercantum dalam Satuan Pembelajaran, khususnya dalam membuat kalimat tanya. Berdasarkan hasil 
evaluasi, hasil belajar yang dicapai siswa tidak mencapai tingkat Kriteria Ketuntasan Minimal (KKM) yang ditetapkan yaitu 65 hanya mencapai 55\% dari jumlah siswa yang ada dan rata-rata nilai ulangan harian siswa hanya mencapai 50 sebesar $60 \%$. Secara umum belum tercapainya Kriteria Ketuntasan Minimal (KKM) pada materi membuat kalimat tanya karena pada umumnya siswa pandai masih sulit untuk bekerja sama dengan temannya yang kurang pandai untuk menyelesaikan soal-soal yang diberikan oleh guru. Prilaku seperti itu dapat tergambar, bahwa sering siswa-siswa menutupi hasil kerjaanya agar tidak dilihat atau tidak dicontek oleh temannya, padahal peristiwa itu berlangsung pada saat guru memberikan penerapan dalam kegiatan belajar mengajar dan bukan pada saat ujian, sementara siswa yang kurang pandai enggan bertanya pada guru.

Keadaan seperti yang dipaparkan di atas, sangat tidak menguntungkan bagi siswa kurang pandai, bagi siswa sedang maupun bagi siswa pandai. Bila keadaan seperti ini berkelanjutan maka akan timbul kelas yang menonton, siswa yang pandai akan menjadi minoritas dan siswa yang kurang pandai akan menjadi mayoritas. Ini tidak baik dalam keefektifan hasil belajar yang diharapkan karena tidak terjadi keseimbangan. Untuk mengubah kondisi yang kurang baik ini, dirasa perlu agar guru/peneliti melakukan suatu tindakan dalam mengorganisir kegiatan pembelajaran di kelas. Dimana siswa yang kurang pandai mau bertanya pada siswa pandai dan siswa pandai mau membantu/memberitahu pada siwa kurang pandai dalam kerja kelompok. Sehingga selama proses pembelajaran dalam rangka membantu siswa yang kurang pandai sesama siswa dalam kelompok akan saling membantu dan bekerja sama. Dengan tujuan agar siswa kurang pandai akan mendapat suatu penguatan daya kelekatan ilmu dalam ingatannya, dengan demikian maka proses pembelajaran akan meningkat.

Tutor Sebaya dikenal dengan pembelajaran teman sebaya atau antar peserta didik. Hal ini bisa terjadi ketika peserta didik yang lebih mampu menyelesaikan pekerjaannya sendiri dan kemudian membantu peserta didik lain yang kurang mampu. Alternatifnya, waktu khusus tiap harinya harus dialokasikan agar peserta didik saling membantu dalam belajar baik satu-satu atau dalam kelompok kecil.

\section{METODE PENELITIAN}

Penelitian tindakan kelas ini dilaksanakan di SD Negeri 25 Lubuklinggau. Waktu penelitian akan dilakukan pada semester ganjil. Penelitian tindakan kelas ini direncanakan terdiri dari dua siklus setiap siklus terdiri dari empat tahapan yaitu perencanaan, pelaksanaan, pengamatan dan refleksi. Observer dalam penelitian tindakan kelas ini adalah 2 orang, yaitu 1 kepala SD Negeri 25 Lubuklinggau, 1 guru kelas SD Negeri 25. Subjek penelitian ini adalah siswa kelas I SD Negeri 25 Lubuklinggau pada semester genap tahun pelajaran 2014/2015, berjumlah dengan 
subjek yang berjumlah 24 siswa yang terdiri dari 11 siswa perempuan dan 13 siswa laki-laki. Perbaikan pembelajaran dilakukan melalui Penelitian Tindakan Kelas (PTK) yang terdiri atas dua siklus. Setiap siklus kegiatan yang dilakukan meliputi : 1) Perencanaan; 2) Pelaksanaan; 3) Observasi / pengamatan; dan 4) Refleksi (Dussuwanda, 2008).

Teknik tes digunakan untuk mendapatkan data utama berupa skor atau nilai tentang peningkatan kemampuan siswa kelas I SD Negeri 25 Lubuklinggau dalam membuat kalimat tanya. Tes ini dilakukan sebanyak tiga kali yaitu pada pratindakan, tindakan siklus I dan tindakan siklus II. Dari ketiga tindakan ini akan dihitung berapa besar peningkatan yang terjadi pada setiap tindakan. Tes yang akan digunakan adalah siswa akan diminta membuat kalimat tanya setelah membaca suatu wacana sebanyak 25 soal dengan nilai maksimal per skor 20 dan skor minimal per skor 0. Dalam menentukan keberhasilan PTK ini peneliti akan mengevaluasi hasil belajar siswa dalam membuat kalimat tanya dengan tes esai membuat kalimat tanya sebanyak 6 buah. Rumus yang digunakan dalam menentukan nilai yang diperoleh siswa adalah

Nilai $=\frac{\text { Skor Soal }}{\text { Skor Maksimal }} \times 100 \quad$ (Depdikbud, 2007)

Sedangkan untuk mengetahui ketuntasan hasil belajar siswa secara umum dalam membuat kalimat tanya, peneliti mempersentasekan jumlah siswa yang mendapat nilai (KKM) 625 ke atas dengan menggunakan rumus persentase sebagai berikut :

$\mathrm{X}=\frac{T}{M} \times 100 \%$

(Depdikbud, 2007)

Keterangan :

$\mathrm{X}=$ Persentase ketuntasan belajar klasikal

$\mathrm{T}=$ Jumlah siswa yang tuntas belajar

$\mathrm{M}=$ Jumlah seluruh siswa dalam kelas

Untuk mengetahui adanya peningkatan pada setiap pengambilan data tes dimulai dari tes pratindakan hingga akhir siklus penelitian, peneliti menggunakan rumus sebagai berikut :

$\mathrm{X}=\frac{R_{2}-R_{1}}{R_{1}} \times 100 \% \quad$ (Depdikbud, 2007) 
Keterangan :

$\mathrm{X}=$ Persentase peningkatan hasil tindakan

$\mathrm{R} 1=$ Nilai rata-rata sebelum tindakan (pratindakan)

$\mathrm{R} 2=$ Nilai rata-rata setelah siklus I dan siklus II

\section{HASIL PENELITIAN}

\section{Deskripsi Kondisi Awal}

Pengambilan data Pra Siklus pada tanggal 13 Oktober 2014 di kelas I SD Negeri 25 Lubuklinggau. Untuk memperoleh data, peneliti memberikan tes yang berupa tugas membuat kalimat tanya. Selanjutnya dalam pengelolaan data yang diperoleh didapat nilai per siswa. Berdasarkan hasil nilai Pra Siklus (terlampir) dapat dilihat bahwa siswa yang mendapat nilai lebih dari 65 (tuntas) dalam tes awal ini sebanyak 14 siswa $(58,33 \%)$ dan yang nilainya kurang dari 65 (belum tuntas) adalah 10 siswa $(41,67 \%)$. Nilai yang tertinggi adalah 75 dan yang terendah adalah 50. Ratarata nilai secara keseluruhan sebesar 63,75. Jadi secara deskriptif dapat dikatakan bahwa kemampuan awal siswa belum termasuk kategori tuntas, karena nilai rataratanya kurang dari 65 dan belum mencapai ketuntasan klasikal 65 sebesar $85 \%$.

Rendahnya nilai tes pada tindakan awal ini disebabkan antara lain, penggunaan metode pembelajaran masih menggunakan metode ceramah, jadi siswa merasa bosan, kurang berminat, dan tidak aktif dalam proses KBM-nya. Atas dasar temuan ini peneliti menyimpulkan bahwa untuk mencapai hasil belajar yang baik, diperlukan satu metode yang dapat menarik minat siswa untuk aktif dalam proses KBM sehingga belajar akan terlihat efisien. Oleh karena itu peneliti mencoba menerapkan metode tutor sebaya. Metode tutor sebaya adalah sebuah prosedur dimana siswa mengajarkan siswa yang lainnya. Tipe yang pertama adalah pengajaran dan pembelajaran dari usia yang sama. Tipe kedua adalah pengajaran yang lebih tua usianya dengan sebaya. Tipe yang lain kadang dimunculkan pertukaran usia mengajar. Hasil pengamatan dan penelitian terhadap kemampuan membuat kalimat tanya pada saat Pra Siklus dapat dilihat pada Tabel 1 berikut:

Tabel 1

Rekapitulasi Nilai Pra Siklus

\begin{tabular}{|c|c|c|c|c|c|}
\hline \multirow[b]{2}{*}{ No } & \multirow[b]{2}{*}{ Nama Siswa } & \multirow[b]{2}{*}{$\mathrm{L} / \mathrm{P}$} & \multirow[b]{2}{*}{ Nilai } & \multicolumn{2}{|c|}{ Keterangan } \\
\hline & & & & Tuntas & $\begin{array}{l}\text { Belum } \\
\text { Tuntas }\end{array}$ \\
\hline 1. & Ajeng Saskia & $\mathrm{P}$ & 65 & $\sqrt{ }$ & \\
\hline 2. & Amanda & $\mathrm{P}$ & 65 & $\sqrt{ }$ & \\
\hline 3. & Auliya Martha & $\mathrm{P}$ & 65 & $\sqrt{ }$ & \\
\hline$\overline{4 .}$ & Celsy Permata Sari & $\mathrm{P}$ & 60 & & \\
\hline
\end{tabular}




\begin{tabular}{|c|c|c|c|c|c|}
\hline 5. & Dede Saputra & $\mathrm{L}$ & 60 & & $\sqrt{ }$ \\
\hline 6. & Diva Gede Seriawan & $P$ & 75 & $\sqrt{ }$ & \\
\hline 7. & Iren Nabila & $P$ & 70 & $\sqrt{ }$ & \\
\hline 8. & Jenike Silviana & $\bar{P}$ & 55 & & $\sqrt{ }$ \\
\hline 9. & Kaylani Dyas & $\mathrm{L}$ & 75 & $\sqrt{ }$ & \\
\hline 10. & M. Dezu Fadhulur & $\mathrm{L}$ & 75 & $\sqrt{ }$ & \\
\hline 11. & M. Farhan Khadafi & $\mathrm{L}$ & 60 & & $\sqrt{ }$ \\
\hline 12. & Marsela Aditya Hakiki & $\mathrm{P}$ & 60 & & $\sqrt{ }$ \\
\hline 13. & Miftahul Huda & $\mathrm{P}$ & 55 & & $\sqrt{ }$ \\
\hline 14. & Mozza Azzhara & $\mathrm{P}$ & 60 & & $\sqrt{ }$ \\
\hline 15. & M. Latif Chaniago & $\mathrm{L}$ & 60 & & $\sqrt{ }$ \\
\hline 16. & Mutiara & $\mathrm{P}$ & 65 & $\sqrt{ }$ & \\
\hline 17. & Nadia Vega & $\mathrm{P}$ & 65 & $\sqrt{ }$ & \\
\hline 18. & Naura Valentina & $\mathrm{P}$ & 65 & $\sqrt{ }$ & \\
\hline 19. & Nayla Aprilia & $\mathrm{P}$ & 70 & $\sqrt{ }$ & \\
\hline 20. & Novia Putri & $\mathrm{P}$ & 65 & $\sqrt{ }$ & \\
\hline 21. & Nur Azizah & $\mathrm{P}$ & 50 & & $\sqrt{ }$ \\
\hline 22. & Nyimas Laura Ramadhan & $\mathrm{P}$ & 55 & & $\sqrt{ }$ \\
\hline 23. & Raditra Raviansyah & $\mathrm{L}$ & 70 & $\sqrt{ }$ & \\
\hline \multirow[t]{4}{*}{24.} & Yudha Renda Jaya & $\mathrm{L}$ & 65 & $\sqrt{ }$ & \\
\hline & Jumlah & & 1530 & 14 & \\
\hline & Rata-rata & & 63,75 & & 10 \\
\hline & $\begin{array}{l}\text { Persentase } \\
\text { Belajar }\end{array}$ & & $5 \%$ & & \\
\hline
\end{tabular}

\section{Deskripsi Siklus I}

Siklus I dilaksanakan 1 kali pertemuan ( 2 x 35 menit) yaitu pada tanggal 20 Oktober 2014 di kelas I SD Negeri 25 Lubuklinggau. Tahap Perencanaan. Pada tindakan pertama ini peneliti melakukan kegiatan pembelajaran dengan penerapan metode tutor sebaya. Hal ini diterapkan sebagai langkah awal untuk meningkaan kemampuan siswa dalam membuat kalimat tanya.

Hasil Pelaksanaan Tindakan. Hasil pembelajaran pada siklus I ini belum mewujudkan keaktifan sebagaimana yang diharapkan. Hasil tes membuat kalimat tanya menujukkan siswa belum mencapai nilai ketuntasan yang diharapkan. Untuk lebih jelasnya hasil pengamatan dan penilaian terhadap kemampuan membuat kalimat tanya dapat dilihat pada Tabel 2 berikut: 
Tabel 2

Rekapitulasi Nilai Hasil Siklus I

\begin{tabular}{|c|c|c|c|c|c|}
\hline \multirow[b]{2}{*}{ No } & \multirow[b]{2}{*}{ Nama Siswa } & \multirow[b]{2}{*}{$\mathrm{L} / \mathrm{P}$} & \multirow[b]{2}{*}{ Nilai } & \multicolumn{2}{|c|}{ Keterangan } \\
\hline & & & & Tuntas & $\begin{array}{l}\text { Belum } \\
\text { Tuntas }\end{array}$ \\
\hline 1. & Ajeng Saskia & $\mathrm{P}$ & 70 & $\sqrt{ }$ & \\
\hline 2. & Amanda & $\mathrm{P}$ & 70 & $\sqrt{ }$ & \\
\hline 3. & Auliya Martha & $\mathrm{P}$ & 70 & $\sqrt{ }$ & \\
\hline 4. & Celsy Permata Sari & $\mathrm{P}$ & 60 & & $\sqrt{ }$ \\
\hline 5. & Dede Saputra & $\mathrm{L}$ & 60 & & $\sqrt{ }$ \\
\hline 6. & Diva Gede Seriawan & $\mathrm{P}$ & 75 & $\sqrt{ }$ & \\
\hline 7. & Iren Nabila & $\mathrm{P}$ & 75 & $\sqrt{ }$ & \\
\hline 8. & Jenike Silviana & $\mathrm{P}$ & 60 & & $\sqrt{ }$ \\
\hline 9. & Kaylani Dyas & $\mathrm{L}$ & 80 & $\sqrt{ }$ & \\
\hline 10. & M. Dezu Fadhulur & $\mathrm{L}$ & 80 & $\sqrt{ }$ & \\
\hline 11. & M. Farhan Khadafi & $\mathrm{L}$ & 65 & $\sqrt{ }$ & \\
\hline 12. & Marsela Aditya Hakiki & $\mathrm{P}$ & 65 & $\sqrt{ }$ & \\
\hline 13. & Miftahul Huda & $\mathrm{P}$ & 60 & & $\sqrt{ }$ \\
\hline 14. & Mozza Azzhara & $\mathrm{P}$ & 65 & $\sqrt{ }$ & \\
\hline 15. & M. Latif Chaniago & $\mathrm{L}$ & 60 & & $\sqrt{ }$ \\
\hline 16. & Mutiara & $\mathrm{P}$ & 70 & $\sqrt{ }$ & \\
\hline 17. & Nadia Vega & $\mathrm{P}$ & 70 & $\sqrt{ }$ & \\
\hline 18. & Naura Valentina & $\mathrm{P}$ & 65 & $\sqrt{ }$ & \\
\hline 19. & Nayla Aprilia & $\mathrm{P}$ & 75 & $\sqrt{ }$ & \\
\hline 20. & Novia Putri & $\mathrm{P}$ & 65 & $\sqrt{ }$ & \\
\hline 21. & Nur Azizah & $\mathrm{P}$ & 55 & & $\sqrt{ }$ \\
\hline 22. & Nyimas Laura Ramadhan & $\mathrm{P}$ & 55 & & $\sqrt{ }$ \\
\hline 23. & Raditra Raviansyah & $\mathrm{L}$ & 70 & $\sqrt{ }$ & \\
\hline \multirow[t]{5}{*}{24.} & Yudha Renda Jaya & $\mathrm{L}$ & 70 & $\sqrt{ }$ & \\
\hline & Jumlah & & 1610 & 17 & \\
\hline & Rata-rata & & 67,08 & & 7 \\
\hline & Persentase Ketuntasan & & 67,08 & & \\
\hline & Belajar & & $\%$ & & \\
\hline
\end{tabular}

Berdasarkan hasil nilai tindakan siklus I (terlampir) dapat dilihat bahwa siswa yang mendapat nilai lebih dari 65 (tuntas) dalam tes ini sebanyak 17 siswa $(70,83 \%)$ dan yang nilainya kurang dari 65 (belum tuntas) adalah 7 siswa (29,17\%). Nilai yang tertinggi adalah 80 dan yang terendah adalah 55. Rata-rata nilai secara keseluruhan sebesar 67,08. Jadi secara deskriptif dapat dikatakan bahwa siklus I siswa belum termasuk kategori tuntas, karena belum mencapai ketuntasan klasikal 65 sebesar 85\%. Namun terjadi peningkatan belajar siswa dari Pra Siklus ke siklus I, hal ini 
terlihat pada nilai rata-rata Pra Siklus sebesar 63,75 sedangkan pada nilai rata-rata siklus I sebesar 67,03 berarti terjadi peningkatan sebesar 3,33 pada Pra Siklus ketuntasan belajar siswa sebanyak 14 siswa $(58,33 \%)$ dan pada siklus I siswa yang tuntas berjumlah 17 orang $(70,83 \%)$. Inipun dapat dilihat terjadi peningkatan yang signifikan sebasar 5,23\%. Secara kuatitatif hasil rata-rata tes akhir siklus I telah meningkat dari 63,75 ke 67,08 yaitu 3,33 (8,62\%). Walaupun hasil akhir siklus I mengalami peningkatan dari rata-rata Pra Siklus, peningkatan itu belum memenuhi daya serap klasikal yaitu : $\quad$ x $100 \%=70,83 \%$. Dengan demikian, hasil tindakan siklus I perlu ditingkatkan.

Hasil Pengamatan. Pelaksanaan siklus I pada penelitian ini diamati oleh 4 orang pengamat yaitu Bapak Marzuki, S.Pd. (Kepala SD Negeri 25 Lubuklinggau) dan Ibu Siti Zubaidah, S.Pd.SD. (Guru Kelas I SD Negeri 25 Lubuklinggau). Berdasarkan hasil observasi para pengamat secara umum pelaksanaan pembelajaran berjalan dengan baik. Walaupun dalam proses pembelajaran yang dilakukan peneliti masih memiliki kelemahan, terutama pada penggunaan waktu dan belum adanya alat peraga. Waktu menjadi kurang efisien karena ketika menjelaskan contoh membuat kalimat tanya, metode yang digunakan kurang efektif karena kurang sosialisasi, sehingga waktu banyak terbuang ketika siswa harus menyusun meja dan kursi untuk buat kelompok. Selain itu, pada awal proses pembelajaran guru tidak menjelaskan tujuan yang ingin dicapai dari proses pembelajaran sehingga pada awal pembelajaran siswa tidak tahu atau bingung apa yang harus dipelajari. Selain itu juga peneliti tidak membuat alat peraga seperti gambar sehingga siswa kurang tertarik sehingga keaktifan siswa dalam kelas tidak tampak. Komentar dan saran yang disampaikan para observer akan dijadikan bahan refleksi dan diterapkan pada siklus berikutnya.

Refleksi. Setelah dilaksanakan siklus I, peneliti memperoleh masukanmasukan atau saran-saran dari para pengamat. Temuan-temuan atau saran-saran tersebut ditindaklanjuti dan langsung ditempatkan pada pelaksanaan siklus II. Sesuai dengan saran-saran atau hasil pengamatan seperti dikemukan oleh para observer dalam siklus I, maka untuk pelaksanaan siklus I, hal-hal yang perlu dibenahi adalah sebagai berikut : pemanfaatan waktu seefisien mungkin, mempersiapkan alat peraga, penyampaian materi yang lebih sistematis dan pemberian motivasi kepada siswa lebih ditingkatkan.

\section{Deskripsi Siklus II}

Perencanaan Tindakan. Tahap perencanaan pada siklus II ini adalah refleksi dari siklus I, hal-hal yang dipersiapkan adalah sebagai berikut : menganalisis materi pengajaran, membuat program satuan pengajaran, membuat program rencana pengajaran, menyiapakan alat peraga, menyiapkan instrumen penelitian, menyiapkan lembar pengamatan dan menyusun posisi kursi dan meja siswa untuk diskusi. 
Pelaksaaan. Sesuai dengan saran-saran yang diperoleh dari siklus I, maka langkah-langkah yang ditempuh pada pelaksanaan siklus II yaitu sebagai berikut : kegiatan awal (15 menit) meliputi; a) guru memeriksa keadaan kelas kemudian dilanjutkan dengan memimpin do'a untuk memulai pelajaran, b) guru memberikan motivasi belajar kepada siswa, c) menjelaskan kompetensi yang akan dibahas dan menghubungkannya dalam kehidupan sehari-hari. Kegiatan inti (40 menit) meliputi; a) guru membagi siswa dalam 3-4 kelompok dengan pembagian dalam kelompok terdapat siswa kurang pandai, siswa sedang dan siswa pandai, b) guru menjelaskan materi tentang membuat kalimat pertanyaan, c) siswa diminta membaca bacaan buku teks masing-masing, d) guru meminta tiap kelompok bekerja secara mandiri dengan dorong siswa pandai dan sedang agar mau membantu siswa yang kurang pandai atau dorong siswa kurang pandai, agar mau bertanya pada tamannya atau guru, e) guru memberikan tes akhir yang harus dikerjakan oleh masing-masing siswa, f) guru membimbing siswa dalam mengerjakan soal latihan. Kegiatan akhir (15 menit) meliputi; a) guru dan siswa mengadakan refleksi terhadap proses belajar, b) menyimpulkan bersama-sama dengan siswa tentang materi yang telah dipelajar

Penilaian hasil belajar siklus I. Pelaksanaan siklus II ini bertujuan untuk memperbaiki kekurangan-kekurangan yang terjadi pada siklus I. Berdasarkan saran pengamat, maka peneliti melakukan perbaikan pada pembagian alokasi waktu dan meningkatkan motivasi siswa dengan menggunakan alat peraga agar lebih efektif. Untuk mengetahui keberhasilan siklus II, peneliti mengadakan tes membuat kalimat tanya yang dikerjakan secara perorangan. Dari hasil tes tersebut akan dilihat nilai keberhasilan siswa pada siklus II. Untuk hasil tes yang ada telah direkapitulasi dapat dilihat pada Tabel 3.

Tabel 3

Rekapitulasi Nilai Siklus II

\begin{tabular}{|c|c|c|c|c|c|}
\hline \multirow[b]{2}{*}{ No } & \multirow[b]{2}{*}{ Nama Siswa } & \multirow[b]{2}{*}{$\mathrm{L} / \mathrm{P}$} & \multirow[b]{2}{*}{ Nilai } & \multicolumn{2}{|c|}{ Keterangan } \\
\hline & & & & Tuntas & $\begin{array}{l}\text { Belum } \\
\text { Tuntas }\end{array}$ \\
\hline 1. & Ajeng Saskia & $\mathrm{P}$ & 80 & $\sqrt{ }$ & \\
\hline 2. & Amanda & $\mathrm{P}$ & 75 & $\sqrt{ }$ & \\
\hline & Auliya Martha & $\mathrm{P}$ & 75 & $\sqrt{ }$ & \\
\hline & Celsy Permata Sari & $\mathrm{P}$ & 70 & $\sqrt{ }$ & \\
\hline & Dede Saputra & $\mathrm{L}$ & 65 & $\sqrt{ }$ & \\
\hline 6. & Diva Gede Seriawan & $\mathrm{P}$ & 85 & $\sqrt{ }$ & \\
\hline & Iren Nabila & $\mathrm{P}$ & 85 & $\sqrt{ }$ & \\
\hline 8. & Jenike Silviana & $\mathrm{P}$ & 65 & $\sqrt{ }$ & \\
\hline 9. & Kaylani Dyas & $\mathrm{L}$ & 90 & $\sqrt{ }$ & \\
\hline
\end{tabular}




\begin{tabular}{lllll}
\hline \hline 10. & M. Dezu Fadhulur & $\mathrm{L}$ & 90 & $\sqrt{ }$ \\
\hline 11. & M. Farhan Khadafi & $\mathrm{L}$ & 75 & $\sqrt{ }$ \\
\hline 12. Marsela Aditya Hakiki & $\mathrm{P}$ & 70 & $\sqrt{ }$ \\
\hline 13. Miftahul Huda & $\mathrm{P}$ & 65 & $\sqrt{ }$ \\
\hline 14. & Mozza Azzhara & $\mathrm{P}$ & 70 & $\sqrt{ }$ \\
\hline 15. & M. Latif Chaniago & $\mathrm{L}$ & 70 & $\sqrt{ }$ \\
\hline 16. Mutiara & $\mathrm{P}$ & 80 & $\sqrt{ }$ \\
\hline 17. & Nadia Vega & $\mathrm{P}$ & 75 & $\sqrt{ }$ \\
\hline 18. & Naura Valentina & $\mathrm{P}$ & 75 & $\sqrt{ }$ \\
\hline 19. & Nayla Aprilia & $\mathrm{P}$ & 85 & $\sqrt{ }$ \\
\hline 20. & Novia Putri & $\mathrm{P}$ & 75 & $\sqrt{ }$ \\
\hline 21. Nur Azizah & $\mathrm{P}$ & 60 & \\
\hline 22. & Nyimas Laura Ramadhan & $\mathrm{P}$ & 60 & \\
\hline 23. Raditra Raviansyah & $\mathrm{L}$ & 85 & $\sqrt{ }$ \\
\hline 24. & Yudha Renda Jaya & $\mathrm{L}$ & 80 & $\sqrt{ }$ \\
\hline Jumlah & & 1805 & 22 \\
\hline Rata-rata & & 75,21 & \\
\hline Persentase Ketuntasan & & $\mathbf{7 5 , 2 0 \%}$ & \\
\hline \hline
\end{tabular}

Berdasarkan hasil nilai tindakan siklus II (terlampir) dapat dilihat bahwa siswa yang mendapat nilai lebih dari 65 (tuntas) dalam tes ini sebanyak 22 siswa (91,67\%) dan yang nilainya kurang dari 65 (belum tuntas) adalah 2 siswa $(8,33 \%)$. Nilai yang tertinggi adalah 90 dan yang terendah adalah 60. Rata-rata nilai secara keseluruhan sebesar 75,21. Jadi secara deskriptif dapat dikatakan bahwa siklus II siswa sudah termasuk kategori tuntas, karena nilai rata-ratanya lebih dari 65 dan memenuhi daya serap klasikal yaitu 91,67\%. Dengan demikian, tindakan siklus I tidak perlu lagi dilaksanakan. Kesulitan dalam membuat kalimat tanya pada siklus I tidak terjadi lagi pada siklus II. Pada siklus II ini siswa mengalami peningkatan dalam membuat kalimat tanya, walaupun ada sebagian kecil siswa yang masih kesulitan dalam membuat kalimat tanya.

Hasil Pengamatan. Pelaksanaan siklus II pada penelitian ini diamati oleh 3 orang pengamat yaitu Bapak Marzuki, S.Pd. (Kepala SD Negeri 25 Lubuklinggau) dan Ibu Siti Zubaidah, S.Pd.SD. (Guru Kelas I SD Negeri 25Lubuklinggau). Berdasarkan hasil pengamatan di atas dapat disimpukan bahwa secara umum proses belajar mengajar dengan penerapan metode tutor sebaya dapat meningkatkan aktivitas belajar siswa. Hal ini dapat dilihat pada antusiasnya siswa dalam menerima pelajaran serta siswa lebih merespon pertanyaan-pertanyaan yang diajukan oleh guru.

Refleksi. Pelaksanaan kegiatan belajar mengajar dengan menggunakan metode tutor sebaya pada siklus II menunjukkan adanya peningkatan, antara lain 
siswa lebih aktif jika dibandingkan dengan pelaksanaan siklus I. Siswa bersemangat dan aktif dalam kegiatan belajar, secara umum siswa memiliki antusias yang tinggi dalam berdiskusi. Melihat suasana pembelajaran yang aktif, maka dapat disimpulkan bahwa metode tutor sebaya dapat meningkatn kemampuan siswa dalam membuat kalimat tanya. Keaktifan siswa dalam kegiatan pembelajaran tersebut menandakan indikator kegiatan pembelajaran telah mencapai yang diinginkan.

Pada siklus II ini rata-rata hasil tes sebesar 75,21 bila dibandingkan dengan nilai rata-rata hasil siklus I sebesar 67,03 meningkat sebesar 8,13 atau $12,11 \%$. Jumlah siswa yang tuntas belajar pada siklus II adalah sebanyak 22 orang $(91,67 \%)$ sedangkan pada siklus I sebanyak 17 orang $(72,22 \%)$. Dengan demikian, terdapat peningkatan siswa yang tuntas sebanyak 5 orang $(20,83 \%)$. Oleh sebab itu, tindakan siklus berikutnya tidak perlu dilaksanakan, karena kriteria ketuntasan secara klasikal $85 \%$ pada tindakan siklus II ini telah tercapai.Keberhasilan tersebut dapat dicapai dengan memperbaiki kekurangan-kekurangan dalam proses pembelajaran siklus I dan penerapan hasil koodinasi dengan dosen pembimbing dan para pengamat dalam penelitian sehingga nilai yang dicapai siswa memperoleh ketuntasan baik secara individu maupuan secara klasikal.

\section{PEMBAHASAN}

Hasil belajar siswa kelas I SD Negeri 25 Lubuklinggau dalam membuat kalimat tanya setelah dilakukan penerapan metode tutor sebaya peneliti paparkan bahwa hasil tes Pra Siklus, hasil tes tindakan siklus I, hasil tes tindakan siklus II terjadi peningkatan. Peningkatan tersebut yaitu peningkatan jumlah siswa yang tuntas belajar dan peningkatan nilai rata-rata hasil tes, rekapitulasinya dapat dilihat di Tabel 4 di bawah ini :

Tabel 4

Perbandingan Ketuntasan Belajar dan Presentase Ketuntasan Dalam Tindakan Penelitian

\begin{tabular}{lllllll}
\hline \multirow{2}{*}{ Nilai Hasil Tes } & Pra Siklus & & Siklus I & \multicolumn{3}{c}{ Siklus II } \\
\cline { 2 - 7 } & Frekuensi & Persen & Frekuensi & Persen & Frekuensi & Persen \\
\hline 65 ke atas & 14 orang & $58,33 \%$ & 17 orang & $70,83 \%$ & 22 orang & $91,67 \%$ \\
\hline 65 ke bawah & 10 orang & $41,67 \%$ & 7 orang & $29,17 \%$ & 2 orang & $8,33 \%$ \\
\hline Jumlah & 24 orang & $100 \%$ & 24 orang & $100 \%$ & 24 orang & $100 \%$ \\
\hline Nilai rata-rata & 63,75 & & 67,03 & & 75,21 & \\
\hline
\end{tabular}

Dari tabel di atas dapat disimpulkan bahwa nilai rata-rata hasil tes pada siklus I jika dibandingkan dengan hasil tes Pra Siklus mengalami peningkatan sebesar 
$5,23 \%$. Sedangkan siswa yang dinyatakan tuntas pada Pra Siklus sebanyak 14 orang $(58,33 \%)$ dan pada siklus I meningkat menjadi 17 orang $(70,83 \%)$, berarti peningkatan siswa yang tutas dari partindakan ke siklus pertama sebanyak 3 orang. Nilai rata-rata hasil tes pada siklus kedua jika dibandingkan dengan siklus pertama juga mengalami peningkatan yaitu sebesar 8,13 atau 12,11\%. Sedangkan siswa yang tuntas dari 17 siswa pada siklus pertama meningkat menjadi 22 siswa pada siklus kedua, berarti terjadi peningkatan dari siklus pertama ke siklus kedua sebanyak 5 orang.

Sedangkan perhitungan peningkatan dari Pra Siklus ke siklus II sebagai berikut :

$\mathrm{X}=\frac{R_{2}-R_{1}}{R_{1}} \times 100 \%$

Keterangan :

$\mathrm{X}=$ Persentase peningkatan hasil tindakan

$\mathrm{R} 1=$ Nilai rata-rata sebelum tindakan (Pra Siklus)

$\mathrm{R} 2=\quad$ Nilai rata-rata setelah siklus I dan siklus II

Maka R1 = 63,75

$\mathrm{R} 2=$ rata- rata siklus $\mathrm{I}=67,08$

rata- rata siklus II $\quad=75,21$

$\begin{aligned} & =\quad 67,08+75,21=142,29 / 2=71,15 \\ X & \times 100 \% \\ = & \quad \times 100 \% \\ = & 0,116078 \times 100 \% \\ = & 11,61 \%\end{aligned}$

Jadi peningkatan dari Pra Siklus ke siklus II sebesar 7,40 atau 11,61\%. Dengan siswa yang tuntas pada Pra Siklus 14 orang setelah dilakukan siklus II menjadi 22 orang, berarti terjadi peningkatan dari Pra Siklus ke siklus II sebanyak 8 orang (data terlampir). Peningkatan hasil belajar sebesar $116,1 \%$ di atas memang tidak terlalu besar. Namun, hal tersebut menunjukkan bahwa hasil belajar per siklus mengalami peningkatan. Dengan demikian penerapan metode tutor sebaya ini mampu meningkatkan kemampuan siswa kelas I SD Negeri 25 Lubuklinggau dalam membuat kalimat tanya.

Faktor-faktor yang menghambat penerapan metode tutor sebaya yang didapat oleh peneliti selama tindakan adalah waktu yang tersedia untuk menyelesaikan bahan, pada penerapannya metode ini membutuhkan waktu yang cukup lama karena peneliti harus bisa mengoptimalkan teman sebaya yang cukup pandai untuk membantu anak yang kurang pandai. Hal ini dapat diatasi dengan dibantunya peneliti dengan guru 
kelas dan teman sejawat dalam mengkoordinir siswa dalam penerapan, siswa yang cukup pandai di pisahkan dengan siswa yang kurang pandai dan kemudian di beri arahan untuk membantu kawannya yang kesulitan dalam memahami pelajaran. Dalam hal ini penerapan tutor sebaya telah dijalankan.

Usaha yang dilakukan oleh individu untuk mengusai bahan tersebut cukup kurang karena di dalam pandangan siswa pelajaran bahasa itu tidak cukup menarik dan membosankan. Sehingga siswa malas dan acuh tak acuh dalam belajar bahasa Indonesia. Hal ini disiasati dengan membuat alat peraga semanarik mungkin untuk menarik siswa sehingga memperhatikan guru yang menjelaskan materi.

Kualitas pengajaran atau tingkat kejelasan guru dalam mengajar yang tidak bisa mengkontrol suasana kelas. Hal ini terjadi pada Pra Siklus dan awal siklus I karena siswa tidak diberi penjelasan penerapan metode tutor sebaya. Namun hal ini tidak terjadi pada siklus II karena pada siklus II sebelum pelajaran siswa telah diberi pemahaman tentang penerapan metode tutor sebaya yang akan mereka jalan.

\section{SIMPULAN}

Berdasarkan hasil penelitian dan pembahasan secara umum dapat disimpulkan bahwa dengan penerapan metode tutor sebaya dapat meningkatkan kemampuan siswa kelas I SD Negeri 25 Lubuklinggau dalam membuat kalimat tanya. Kemampuan siswa dalam membuat kalimat tanya mengalami peningkatan. Hal ini dapat dilihat dari rata-rata nilai pada setiap tindakan. Rata-rata nilai pratindakan sebesar 63,75 , pada siklus I rata-rata nilai yang di dapat meningkat menjadi 67,08. Sedangkan hasil rata-rata pada siklus II meningkat lagi menjadi 75,21. Besarnya peningkatan kemampuan membuat kalimat tanya melalui metode tutor sebaya dari pratindakan sampai akhir siklus II dengan menggunakan rumus $\mathrm{X}=\mathrm{x} 100 \%$ di dapat peningkatan sebesar $11,61 \%$. 


\section{DAFTAR PUSTAKA}

Mafaza, A. (2003). Penerapan Metode Tutor Sebaya dalam Meningkatkan Keterampilan Membuat Pengumuman Siswa Kelas V SD Negeri 006 Cibubur. Bandung : Unpad. (http://indoksripsi.com).

Depdikbud. (2007). Garis-garis Besar Pengajaran. Jakarta: Balai Pustaka.

Dossuwanda. (2008). Metode Pengajaran dan Penelitian. Jakarta: Alpabheta.

Hadiningsih. (2004). Penerapan Feer Tutor Method dalam Meningkatkan Keterampilan Membuat Puisi Siswa Kelas III SD Negeri 237 Cimahi. Bandung : Unpad. (http://indoksripsi.com). 